\title{
Started From The Bottom, Now We're Here: Navigating the Job Market Without A “Top Tier" PhD
}

Rachel E. Finnell

Bethany College

\section{Alexandra T. Middlewood \\ Wichita State University}

Being on the job market is one of the most precarious and daunting tasks one faces during their graduate career. Earning a $\mathrm{PhD}$ from outside a "top tier" program may add additional — albeit often unnecessary — stress. As an upcoming graduate of a non-top tier program, the challenges one faces can be dramatically different than others navigating the job market. Graduating from a top tier program is not a requisite for success. Both authors graduated from a non-top tier program and obtained tenure track jobs immediately, though at very different types of institutions - one author teaches at a small religious liberal arts college while the other teaches at a medium-sized R2 public university. Thus, we offer first hand evidence and experience on what helped us be successful on the job market.

In this chapter, we discuss the quandary with program rankings, provide considerations for setting beneficial goals for tackling the job market, offer guidance on creating and utilizing academic networks, and discuss the teaching versus research debate. This manuscript is part of Strategies for Navigating Graduate School and Beyond, a forthcoming volume for those interested in pursuing graduate education in political science (Fall 2022 publication)

\section{Program Rankings}


The ranking of one's doctoral program does not determine success on the academic or non-academic job market. Make no mistake, program rankings exist, and they do matter to some extent, but they are only one factor of job market success. Focusing on program rankings often overlooks what those rankings tell us about job market trends. The most recent APSA Graduate Placement Report: Analysis of Political Science Placements for 2017-2018 report available provides some insight into the state of the political science job market prior to the COVID-19 pandemic. While there is not an abundance of data available on political science graduate placements, this report does provide a glimpse into overarching trends in job market placements for the 2017-2018 academic year. According to the report, top tier programs are much more likely to place candidates into postdoctoral positions. In the top twenty percent of political science $\mathrm{PhD}$ programs — as ranked by the National Research Council — nearly sixty-two percent of candidates accepted postdoctoral positions for their first placement. The report indicates that these candidates were sixteen percent more likely to take a postdoctoral placement than a tenure track job. Of all job candidates that accepted tenure track positions, only forty-six percent were from those top programs. The remaining fifty-four percent of candidates who accepted tenure track positions came from non-top tier programs.

These placements suggest that most PhD programs know their strengths. Top tier programs tend to be heavily focused on research, and as such they encourage their candidates to seek out postdoctoral positions to further develop research skills and are quite successful in those placements. Additionally, it is well known throughout the discipline that top tier $\mathrm{PhD}$ programs tend to hire job candidates from other top programs. Whereas the placements of non-top tier candidates are more varied. $\mathrm{PhD}$ students at mid-range or lower ranked programs should expect 
to have greater chances of being hired at programs ranked lower than the one attended for doctoral studies. Most often, these candidates will be successful in political science departments without PhD programs. The sheer number of political science programs with only undergraduate or undergraduate and masters' programs far outnumber those that grant $\mathrm{PhDs}$. There are certainly instances where mid-tier candidates do successfully get hired in $\mathrm{PhD}$ granting departments but doing so is often out of the norm.

Again, these trends speak to the fact that most $\mathrm{PhD}$ programs know their own strengths and utilize that knowledge to benefit their students on the job market. As such, non-top tier students often take a different path throughout graduate school than their top tier counterparts. Mid-tier and lower ranked $\mathrm{PhD}$ programs tend to have a strong teaching focus alongside research. Mid and lower range programs know that their students will be most successful at institutions that emphasize teaching and often underscore the importance of getting this experience while in graduate school, especially as an instructor of record. When teaching-focused departments hire new faculty, having classroom experience can be extremely advantageous for job candidates. As this teaching emphasis is generally not found within top tier programs, candidates from lower ranked programs have a distinct advantage over candidates from higher ranked $\mathrm{PhD}$ programs.

Knowing the job placements of prior graduates is helpful to setting job market goals. For example, the authors' doctoral program has been very successful at placing students into tenure track jobs at teaching-focused institutions and liberal arts colleges, with a few placements at R2 and mid- or low-tier R1 institutions. Recognizing this, we were able to set realistic job market goals and develop targeted experiences that ultimately helped secure tenure track jobs. If there is 
any uncertainty about previous job placements within one's department, it is advantageous to speak with other graduate students, the graduate director, professors, and one's advisor about this information.

\section{Setting Beneficial Goals for the Job Market}

When it comes to being successful on the job market, one of the most valuable things a PhD student can do is to set goals early. These goals should include deciding an area(s) of specialization and whether the goal is an academic or non-academic career path. The sooner these decisions are made, the more direction doctoral students will have throughout their graduate career and beyond. Not only will this help guide one's path towards the job market, but it will help align decisions throughout graduate school with one's job market goals — such as teaching vs. research.

These decisions can be made in consultation with one's advisor, mentors, or on one's own. Seeking advice from advisors, and other academic mentors, can help significantly with this goal-setting process. Some faculty are more attuned to academic trajectories while others to non-academic careers; some are more research focused while others put more emphasis on teaching. As a result, seeking advice from multiple advisors/mentors to gain different perspectives can be beneficial when making a decision. Though, we want to emphasize that a PhD student's desired career outcome should reign supreme. If an advisor is not supportive of a student's goals post-PhD, then an alternative advisor, or additional mentors, may be necessary. Importantly, it is okay to find alternative mentors and/or advisors should a current one no longer be a healthy fit or supportive of the student's overall vision for their future - whether it be due 
to focusing on teaching, research, other professional choices being made, or possible personality clashes.

First and foremost, choosing an area of study is particularly important. Generally, departments tend to specialize in certain research areas that graduate students will often gravitate towards. While it is of course possible to study a topic outside of one's advisor's specialty, we do not recommend it. The experience necessary to succeed on the job market with a research agenda outside the norm for the department and/or advisor does not always lead to disaster - some graduate students can and do excel in this type of environment. However, most benefit substantially by focusing on the research specialty of their department. Networking and co-authored publications are more easily attained when a graduate student's area of research aligns with their advisor. For these reasons, deciding an area of specialization as soon as possible is a critical step in the job market process.

\section{Academic and Non-Academic Career Choices}

In addition, decide as early as possible about the academic versus non-academic career question. When choosing a career path, it is important to understand the diversity which each of these paths provide. From different types of institutions in the academic realm to a blossoming job market in the non-academic sector, a graduate degree in political science is a valuable and useful asset for your future career plans.

The heterogeneity of institutions and career choices include everything from tenure-track to adjuncting as well as institutions from R1 to community college. Regardless of the type of academic job, networking is critical. Frequently, the key to being hired for an academic job is having connections at several different institutions. This is especially true when graduating from 
a non-top-tier program. While there is no "right" way to network, regional networking is very effective for obtaining teaching-focused positions. These connections can be made through smaller regional and/or state political science conferences, online through Twitter or LinkedIn, and to some extent during large conferences. Most non-top tier PhD programs are very successful at placing graduates at regional institutions. As a result, networking with prior graduates, especially those who are employed at local colleges and universities, can be invaluable and even lead to job placement. Furthermore, it is common for $\mathrm{PhD}$ students in non-top tier programs to adjunct at local institutions, including community colleges, during graduate school. Not only do these positions bolster curriculum vitaes but also establish connections at several types of local institutions that can be beneficial when navigating the academic job market.

The choice to take an academic career path can often drive the need for outside teaching experiences - that is being an instructor of record at an institution outside of one's $\mathrm{PhD}$ granting institution. This experience is especially important for graduates from non-top tier $\mathrm{PhD}$ programs. Being an instructor of record at an area community college, college, or university provides a more diverse skill set than only having experience as a teaching assistant. Students at large universities are generally quite different, in terms of their lived experiences and their academic and personal needs, from those who attend community colleges or small liberal arts institutions. When outside teaching opportunities are not possible - as is often the case for international students - teaching multiple courses as an instructor of record at one's own institution is extremely beneficial. Having this diverse teaching experience, as well as a background developing and teaching courses, signals to hiring committees that candidates will 
have less of a learning curve and as such this experience is immensely beneficial on the job market.

On the other hand, finding a career in the non-academic sector is a viable choice. In fact, several career opportunities are available for those who decide that teaching is not their goal. Most often, the private sector offers jobs centered around data analysis or other skills you have learned throughout graduate studies. The reality is being a social scientist prepares doctoral students well for the diverse challenges the world faces. Maybe you want to work for the government, a nonprofit organization, think tank, or large corporation? These are all excellent career choices that a graduate degree in Political Science prepares you for.

\section{The Great Debate — Teaching vs. Research}

Where should graduate students focus their time? Is it more advantageous to take on additional teaching responsibilities or should research be the focal point? The ultimate answer to these questions is it depends. It depends on the career goals discussed in the previous section will it be academic or non-academic? Additionally, it is important to note that these are extremely broad categories and there is much variation within those silos. This variation, and the ultimate outcome, underscores why setting career goals early is essential for all PhD candidates. These choices provide costs and benefits that must be weighed as a graduate student. While research is important for one's work as a scholar and in the discipline, the authors know firsthand that research and publications do not define one's job market prospects. Every academic career is different.

Teaching Experience 
If one chooses the academic route, one of the most important things a graduate student from a non-top tier program can do is diversify the courses they teach and seek instructor of record opportunities. The reality is, there are more teaching institutions in the United States than there are research intensive universities. While most political science departments will have some research expectations, a majority will focus more, or equally, on teaching. These are the types of institutions where non-top tier PhD students are most likely to be hired, and therefore starting to prepare for that experience while in graduate school is beneficial. To note, the decision to focus on gaining teaching experience can be a controversial one, mostly because it is a different path than faculty at $\mathrm{PhD}$ granting institutions experienced. If one's advisor is ill-equipped to offer advice on teaching experience, students should seek out mentorship from other faculty, either in their department, at conferences, or other academic social networking opportunities.

One key to a successful job market experience is to be the instructor of record for numerous courses. If these courses are across subfields, it is even more beneficial. Note that subfields do not need to necessarily be one's area of study. For example, most political science professors are needed for general education and degree requirement fulfilling courses like American Government. As a Political Scientist, one should be well equipped to teach an Introduction to Political Science course which provides a general survey of the field itself, regardless of individual specialization. Courses such as these are useful additions to any teaching portfolio. Other introductory courses include Introduction to Comparative Politics and Introduction to International Relations. While those who major in these subfields are likely better equipped to teach the courses, having the ability to teach multiple introductory courses can give 
non-top tier candidates a leg up, particularly with smaller-sized departments where all faculty teach introductory courses.

Courses beyond introductory are also helpful to teach as a graduate student. In fact, upper-level courses can be some of the most insightful and exciting courses professors teach. Often, these courses are focused on more specific topics and specialty knowledge — frequently from a dissertation topic or research agenda. For those graduate students most interested in teaching upper-level undergraduate courses and Masters or PhD level courses, these courses can be particularly valuable in a teaching portfolio. From influencing the formation of a teaching statement to growth in teaching pedagogy, teaching is deeply beneficial for graduate students from non-top tier programs. Diverse teaching experience should be highlighted as a unique strength in application materials. Further, speaking with one's advisor is a great way to decide which sorts of courses taught would speak to individual strengths and the current needs of the department.

While teaching and developing multiple courses during graduate school is a lot of additional work, it is invaluable to job candidates applying to teaching-focused departments. It shows the hiring committee that the candidate has experience developing coursework, teaching classes, and building rapport with students. It can also provide additional teaching evaluations to include with application materials. ${ }^{1}$ While not the focus of this chapter, or even this publication, having teaching experience can also be extremely beneficial beyond graduate school. In an academic job, it serves the benefit of creating less course prep — we found this extremely helpful when trying to navigate new jobs and campuses. Additionally, teaching experience can

\footnotetext{
${ }^{1}$ The authors acknowledge the vast depth of research that has been conducted on discriminatory bias and teaching evaluations (e.g. Chávez and Mitchell 2020), but unfortunately, evaluations are still currently used as a measure of teaching effectiveness and are often requested as part of academic job applications.
} 
also be beneficial in a non-academic job. Classroom teaching skills can easily translate to experience with meeting administration and conflict resolution, which are valuable in any career field.

\section{Research Experience}

While most non-top tier PhD students are hired at teaching focused institutions, most still have some research requirements. Therefore, gaining research experience while in graduate school is still useful. Research allows new scholars to sharpen their skills and distinguish their dissertation and research interests within the field of political science.

Research skills develop most while writing the dissertation. When selecting a dissertation topic, it is important to choose a topic that is both enjoyable and interesting. Given the emphasis on teaching at most colleges and universities where non-top tier candidates frequently obtain jobs, it can also be advantageous to choose a dissertation topic that is applicable to multiple subfields and teaching areas. For example: using mixed methods within a dissertation; choosing a topic that could connect to several types of courses, like public opinion or political behavior; or even choosing an interdisciplinary topic. The dissertation phase is the best time to be creative with research and figure out what is enjoyable. Choosing a dissertation topic will naturally extend beyond the research realm and into the classroom.

From the dissertation there are opportunities to present at conferences and publish. Networking at conferences is a great way to meet future coauthors, gain exposure to new research in the discipline, build confidence as an upcoming scholar, and create connections that can be helpful on the job market. Additionally, research completed during a $\mathrm{PhD}$ can sometimes count towards tenure while also aiding in the development of knowledge in the field. Overall, 
having research experience in addition to teaching experience, can only help one's job market chances as a graduate of a non-top tier program and as such is worthy of time and effort while in graduate school.

\section{Conclusion}

Navigating the job market from a mid- or lower-tier $\mathrm{PhD}$ program is not as dire as it is sometimes made out to be. In fact, students can be very successful on the academic job market and graduating from a top tier institution is not a requisite for a tenure track job. The keys to success are setting clear obtainable goals, seeking outside teaching experience, and highlighting unique strengths and experiences in job applications. One of the most significant tasks necessary as a graduate student at a non-top tier program is to network as much as possible. While following the advice presented in this chapter will not guarantee a job, we hope it makes the process less uncertain and provides graduate students from non-top tier political science programs with a roadmap to help navigate the job market.

\section{Works Cited}

Chávez, Kerry, and Kristina M.W. Mitchell. 2020. "Exploring Bias in Student Evaluations: Gender, Race, and Ethnicity." PS: Political Science \& Politics 53(2): 270-74.

McGrath, Erin, and Megan Davis. 2019. APSA Graduate Placement Report: Analysis of Political Science Placements for 2017-2018. Politics and International Relations. preprint. 
https://preprints.apsanet.org/engage/apsa/article-details/5d2dd689f4cf65001aa0744b

(August 11, 2021). 